Winter 2014

\title{
Targeted Drug Donations: A Necessary Evil in Need of a Global Harness and a Possible Cure for TRIPS Shortcomings
}

\author{
Gabriella Tzeneva \\ Indiana University Maurer School of Law, gtzeneva@indiana.edu
}

Follow this and additional works at: https://www.repository.law.indiana.edu/ijgls

Part of the Food and Drug Law Commons, International Law Commons, and the International Trade Law Commons

\section{Recommended Citation}

Tzeneva, Gabriella (2014) "Targeted Drug Donations: A Necessary Evil in Need of a Global Harness and a Possible Cure for TRIPS Shortcomings," Indiana Journal of Global Legal Studies: Vol. 21 : Iss. 1 , Article 14.

Available at: https://www.repository.law.indiana.edu/ijgls/vol21/iss1/14

This Note is brought to you for free and open access by the Law School Journals at Digital Repository @ Maurer Law. It has been accepted for inclusion in Indiana Journal of Global Legal Studies by an authorized editor of Digital Repository @ Maurer Law. For more information, please contactrvaughan@indiana.edu.

\section{$\Psi$}

JEROME HALL LAW LIBRARY

INDIANA UNIVERSITY

Maurer School of Law
Bloomineton 


\title{
Targeted Drug Donations: A Necessary Evil in Need of a Global Harness and a Possible Cure for TRIPS Shortcomings
}

\author{
GABRIELLA TZENEVA*
}

\begin{abstract}
This Note explores the economic and social factors that drive multinational pharmaceutical companies to donate drugs to developing countries and evaluates the effectiveness of such donations in combating medicine shortages. The Note poses that such donations provide necessary economic incentives to drug companies and help curb high medical prices in developed nations while being an essential tool for ameliorating intellectual property requirements imposed by TRIPS. The Note proposes two solutions to further incorporate donations in access to medicine relief efforts and advocates increased international cooperation in the practice.
\end{abstract}

\section{INTRODUCTION}

It is no secret that the world is confronted with a global health care crisis that pervades nations to varying degrees depending on their economic status and social structure. Yet, our society has somehow grown numb to the numbers. Currently, a third of the world's population lacks access to vital medicine that could prevent millions of excruciating deaths each year. ${ }^{1}$ In developing countries, children are dying of preventable diseases that could be cured with appropriate

* Articles Editor, Indiana Journal of Global Legal Studies; J.D. 2014, Indiana University Maurer School of Law. I would like to thank my friends and family for their support and Professor Phil Purcell for his advice and assistance.

1. Alain Guilloux \& Suerie Moon, Hidden Price Tags: Disease-Specific Drug Donations: Costs and Alternatives 189 (Feb. 1, 2001) (unpublished working paper), available at $\mathrm{http} / / \mathrm{www}$.deolhonaspatentes.org.br/media/file/publicacoes/hidden_price_tags .pdf.

Indiana Journal of Global Legal Studies Vol. 21 \#1 (Winter 2014)

(c) Indiana University Maurer School of Law 
treatment. ${ }^{2}$ But is that shocking? Or have we resolved to accept such conditions as an insoluble fact of life? At home, the United States is faced with rising health care costs, and if the struggle over the passage of the Affordable Health Care Act is any indication, ${ }^{3}$ achieving affordable access to health care remains on the forefront of the national health crisis. Considering the importance of a worldwide effort to improve access to essential medicines, the practice of pharmaceutical donations, what drives them, and how they can be best harnessed warrants further attention.

Drug donations have been historically controversial due to the largely decentralized nature of the process and the variety of donations that currently exist. From "inventory dumping" to "corporate welfare," the motives of drug companies' philanthropic efforts have been closely scrutinized since the beginning of the practice. Many inappropriate donations have been dubbed "drug dumping"5 and have undoubtedly had a devastating impact on recipient countries left to deal with the costly disposal of unsuitable and sometimes expired products. ${ }^{6}$ Attempting to "improve the quality of medicine donations" and ensure effectiveness, ${ }^{7}$ in 1996 the World Health Organization (WHO), in conjunction with other international agencies, issued its first set of advisory guidelines, ${ }^{8}$ which have since had arguable success. ${ }^{9}$ It is worth noting, however, that the cause of most inappropriate donations has not been proven to be corporate misfeasance. ${ }^{10} \mathrm{~A}$ combination of factors, including the lack of communication between donors and receivers, the over- or underestimation of medical needs, and the lack of a formalized

2. See Graham Dutfield, Delivering Drugs to the Poor: Will the TRIPS Amendment Help?, 34 AM. J. L. \& MED. 107, 107 (2008).

3. Patient Protection and Affordable Care Act, Pub. L. No. 111-148, 124 Stat. 119 (2010), amended by Health Care and Education Reconciliation Act of 2010, Pub. L. No. 111-152, 124 Stat. 1029 (codified as amended in scattered sections of 42 U.S.C.).

4. Glenna Crooks, Drug Donations: Protecting Industry Philanthropy, PHaRMaceuticaL EXECUTIVE, Aug. 1998.

5. See David Szostak, Book Note, Global Pharmaceutical Industry: Ensuring Profits at the Expense of Public Health, 13 DePaUl J. Health CARE L. 103, 114-15 (2010).

6. See Philippe Autier et al., Drug Donations in Post-Emergency Situations, WorLD Bank Health, Nutrition \& POPUlation Discussion PaPER SERIES 1 (June 2002), http://siteresources.worldbank.org/HEALTHNUTRITIONANDPOPULATION/Resources/2 81627-1095698140167/Nassery-DrugDonation-whole.pdf.

7. WORLD HEALTH ORG., GUIDELINES FOR MEDICINE DONATIONS 3 (3d ed. 2011), available at http://whqlibdoc.who.int/publications/2011/9789241501989_eng.pdf [hereinafter WHO GUIDELINES].

8. Id.

9. See Autier et al., supra note 6, at 22; Radha Asher et al., First-Year Experiences with the Interagency Guidelines for Drug Donations, WORLD HEALTH ORG. (2000), http://apps. who.int/medicinedocs/en/d/Jwhozip50e/7.html [hereinafter WHO Guidelines Evaluation].

10. See Crooks, supra note 4 . 
process, have been established as the leading causes of failed donation efforts. ${ }^{11}$ In addition, the majority of improper donations involve aid in response to international crisis situations, including events similar to the Haiti earthquake or the South Asian tsunami, ${ }^{12}$ not donations for developmental purposes, which are the focus of this Note.

Although donations as a whole have gained a bad reputation and pharmaceutical companies have largely taken the brunt of criticism due to the nature of the donated products and lack of accountability mechanisms, ${ }^{13}$ targeted donations for long-term developmental purposes have had significant success in combating a number of endemics. ${ }^{14}$ Despite shortcomings regarding the quality and effectiveness of donations, ${ }^{15}$ which all interested stakeholders should address with concerted effort, drug donations play a number of important roles and are therefore a necessary evil that should be properly regulated but not discouraged.

In particular, the potential of targeted donations to remedy the shortage of medicine as a result of the Trade Related Aspects of Intellectual Property Rights (TRIPS) ${ }^{16}$ agreement and the Doha Declaration ${ }^{17}$ is significant in light of balancing the importance of protecting pharmaceutical intellectual property rights while taking into account the ability of developing countries to meet international standards without jeopardizing their medical needs. To that end, this Note presents an expose of the economic and social factors behind corporate donations and considers how these incentives can be best employed to ameliorate the shortage of medicine that currently exists in developing countries. Part I provides an overview of the pharmaceutical industry and discusses the social and economic factors motivating drug companies to donate. Part II briefly outlines the nature of targeted development donations by discussing existing programs and their

11. See WHO GUIDELINES, supra note 7, at 6-7.

12. See Autier et al., supra note 6, at 3.

13. See generally Crooks, supra note 4 (stating that pharmaceutical companies are often blamed for failed donations) (also stating that many donations cannot be traced to the original donors due to lack of formality and proper procedures between all the actors involved in the process; and that as a result, the easiest scapegoats in cases of impropriety are manufacturers, whose information is imprinted on the drug, although they are not the original source of the donation and have limited control over its quality once it leaves their possession).

14. See infra Part II.

15. See WHO Guidelines Evaluation, supra note 9.

16. See Agreement on Trade-Related Aspects of Intellectual Property Rights, Apr. 15, 1994, Marrakesh Agreement Establishing the World Trade Organization, Annex 1C, 1869 U.N.T.S. 299 [hereinafter TRIPS Agreement].

17. See World Trade Organization, Ministerial Declaration of 14 November 2001, WT/MIN(01)/DEC/1, 41 I.L.M. 746 (2002) [hereinafter Doha Declaration]. 
success. Part III summarizes the post-TRIPS environment and points to key aspects of the agreement that make access to medicines difficult for developing countries despite a compulsory licensing exception. Finally, Part IV outlines recommendations on how targeted donations can remedy the access problem, including the use of a voucher system as a complement to tax deductions.

\section{Behind DRUg Donations From a CoRPoRAte Perspective: WhY DONATE?}

To further appreciate the importance and potential benefits of drug donations, it is essential to consider the driving factors behind them. Reasons for pharmaceutical donations are often oversimplified to accusations of "corporate welfare," 18 but realistically the prospects of a tax break do not fully capture the environment in which pharmaceutical companies operate and why financial incentives are critical in promoting the practice. ${ }^{19}$ Considering the overwhelming public and academic backlash against donations, ${ }^{20}$ which often ends in publicity nightmares for pharmaceutical companies, ${ }^{21}$ it is striking that such programs have continued to grow in the past decade. ${ }^{22}$ This growth suggests that both economic and altruistic motives drive donations and, therefore, considering the efficacy of existing programs to ameliorate access to medicine, it is worth taking a more objective view toward such philanthropic initiatives.

\section{A. The Impact of Generics and Insurance Companies on the Need to Donate}

Although the precise impact of generics and insurance companies on brand-name drug companies is disputed, ${ }^{23}$ most experts agree that

18. Crooks, supra note 4. Corporate welfare refers to government subsidies for corporate entities. The term is usually used in a derogatory fashion to compare corporate subsidies to welfare payments for the poor.

19. See id. (noting that the U.S. encourages private philanthropy through its tax code as a matter of public policy). It is important to point out that the tax break this Note refers to only applies to U.S.-based companies under the American Corporate Income Tax system.

20. See generally Richard Aplenc et al., Letters to the Editor, Inappropriate DrugDonation Practices in Bosnia and Herzegovina, 338 NEW ENG. J. MED. 1472, 1472-74 (1998).

21. See Crooks, supra note 4.

22. Id.

23. See generally U.S. CONG. BUDGET OFFICE, EFFECTS OF USING GENERIC DRUGS ON MEDICARE'S PRESCRIPTION DRUG SPENDING (2010) [hereinafter EFFECTS OF GENERICS], 
competition with generic producers and insurance companies' overall preference for generics inevitably exerts pressure on profit margins. ${ }^{24}$ Based on that premise, donations help recuperate losses and research and development costs that are forfeited when generic producers detract market share away from brand-name drugs after a lengthy and expensive patent process, ${ }^{25}$ and insurance companies, as well as government programs, use generic substitution to curb costs. ${ }^{26}$

Generic drugs are "chemically equivalent versions of brand-name drugs that can be approved under an abbreviated regulatory process." 27 The abbreviated process refers to a section of the Hatch-Waxman Amendments of the Drug Price Competition and Patent Term Restoration Act of $1984 .{ }^{28}$ Under section 101 of the Act (amending section 505 of the Federal Food, Drug, and Cosmetic Act), ${ }^{29}$ an abbreviated new drug application (ANDA) approval process allows generic versions of previously approved brand-name drugs to enter the market, bypass the "costly clinical trials" originally conducted, ${ }^{30}$ and gain approval as long as the generic "contains the same active ingredient as the brand-name version" and "provides very similar concentrations of the drug in the blood." ${ }_{11}$ In addition, an ANDA applicant under paragraph IV of 502(j) ${ }^{32}$ may be protected from competition from subsequent generic versions for 180 days after either the first marketing of the original generic or a court decision holding the brand name patent to be invalid or not infringed. ${ }^{33}$ This protection for

available at http://www.cbo.gov/sites/default/files/cbofiles/ftpdocs/118xx/doc11838/09-15-pr escriptiondrugs.pdf.

24. See id. at 9-10.

25. See id.

26. Id. at 7, 13 (referring to Medicare programs using generic substitution and explaining that "[i]n 2007, about 65 percent of Part D prescriptions were filled with generic drugs, but those prescriptions accounted for about one-quarter of total prescription drug costs").

27. Id. at 8.

28. Drug Price Competition and Patent Term Restoration Act of 1984, Pub. L. No. 98417, 98 Stat. 1585 (codified as amended in scattered sections of 21 U.S.C. and 35 U.S.C.) [hereinafter Drug Price Competition Act] (the Hatch-Waxman Amendments).

29. Id. $§ 101$.

30. EFFECTS OF GENERICS, supra note 23, at 8.

31. Id.

32. An ANDA applicant must include in the ANDA a patent certification as described in section 505(j)(2)(A)(vii) of the Act. The certification must make one of the following statements: (I) no patent information on the drug product that is the subject of the ANDA has been submitted to FDA; (II) such patent has expired; (III) the date on which such patent will expire; or (IV) such patent is invalid or will not be infringed by the manufacture, use, or sale of the drug product. Drug Price Competition Act $\$ 101$.

33. U.S. DEP'T OF HEALTH \& HuMAN SERVS., FOOd \& DRUG ADMIN. CTR. For DRUG EVALUATION \& RESEARCH, GUIDANCE FOR INDUSTRY: 180-DAY GENERIC DRUG EXCLUSIVITY 
generic producers is commonly referred to as "180-day exclusivity." 34 Also, the overall impact of generics is to either increase or decrease the price of the brand-name drug, ${ }^{35}$ with either option adversely affecting the profit margins of brand name producers. Because generic producers can afford to price their products on average at $75 \%$ off the price of brand-name drugs, 36 they are able to "capture a large share of the market." 37 In 2010 , generics "captured $80 \%$ of a brand's volume within six months of patent loss." 38

Moreover, research has demonstrated that generic entry lowers total spending on the drug for both generic and nongeneric versions due to a decrease in the average price of the drug. ${ }^{39}$ Therefore, although generics are arguably necessary to offset high prices and total medical spending, ${ }^{40}$ it is important to acknowledge the negative effect they have on profits of nongeneric producers who are forced to bear the costs of research and development and hope to make up for such costs before competition with generics ensues.

The aforementioned scenario is repeated when insurance companies and government programs exercise a preference for generic products. ${ }^{41}$ The process of generic substitution involves the "switching [of] a prescription from a brand-name drug to a less expensive chemically equivalent generic drug." 42 Substitution is possible because once a drug is available in a generic version, pharmacists can dispense either the generic or the brand-name drug, ${ }^{43}$ and generics are often used by health insurers to lower their spending on prescription drugs. ${ }^{44}$ Although some regulations require pharmacists to get consent from patients or at least inform them of the substitution, ${ }^{45}$ health insurers receive help from pharmacies that have an interest in boasting lower prices by supplying

Under the Hatch-WaXman Amendments to the Federal FoOd, DRUG, and Cosmetic ACT 2 (1998) [hereinafter FDA GUIDANCE].

34. Id.

35. EFFECTS OF GENERICS, supra note 23 , at 10.

36. Id. at 8-9.

37. Id. at 10 .

38. James Brumley, What's the Real Impact of Generic Drugs?, INVESTORPLACE (June 28, 2012, 11:57 AM), http://investorplace.com/2012/06/whats-the-real-impact-of-generic-dr ugs/.

39. See EFFECTS OF GENERICS, supra note 23, at 11.

40. See Brumley, supra note 38 (explaining that in 2010 , "generic drugs saved the U.S. more than $\$ 158$ billion in prescription costs").

41. See generally EFFECTS OF GENERICS, supra note 23.

42. Id. at 1 .

43. Id. at 9 .

44. Id.

45. Id. 
generics. ${ }^{46}$ In 2011 , generics made up a staggering $80 \%$ of prescription drug sales in the United States, reflecting an increase from previous years. ${ }^{47}$

In addition, insurance companies are allowed to promote generic substitution by using a list of covered drugs on their insurance policies, which may directly exclude some brand names from coverage or charge a lower copayment for generics. ${ }^{48}$ Unfortunately, substitution, although helpful to consumers' pocketbooks, carries risks in cases when physicians specifically prohibit the use of generics, such as in the treatment of epilepsy. ${ }^{49}$ Overall, it appears that generics and insurance companies have an effect on the pharmaceutical industry, although the precise losses are difficult to measure and are certainty debatable.

\section{B. Economic Incentives: Tax Deductions}

Considering the environment in which pharmaceutical companies operate, it is understandable that companies take advantage of tax breaks for certain qualifying charitable donations in order to offset losses. ${ }^{50}$ The tax incentive refers to a tax deduction under Internal Revenue Code Section 170(e)(3). ${ }^{51}$ Commonly referred to as an "enhanced deduction," the Tax Code allows companies to benefit from an essentially public subsidy if certain conditions are met. ${ }^{52}$ To qualify for the tax break, the donated product must be "used ... solely for the care of the ill, the needy, or infants"53 and must comply with FDA regulations. ${ }^{54}$ The drug must also be "sellable" or have a "fair market value." 55 Due to that requirement, drug samples or expiring/expired drugs would not qualify for the deduction because there is no readily available market-no hospital or facility would normally buy such drugs. ${ }^{56}$ Although the Tax Code does not currently require compliance

46. Id.

47. Brumley, supra note 38 .

48. EFFECTS OF GENERICS, supra note 23, at 9.

49. See id, at 8 .

50. See, e.g., James B. Russo, Drug Donations: What Drives Them? Should They Be Driven? Policy Implications of A Debated Practice, PARTNERSHIP FOR QUALITY MED. DONATIONS 2 (Jan. 6, 2008) http://www.pqmd.org/assets/PDFs/drug_donations-policy_imp lications_of_a_debated_practice.pdf.

51. See I.R.C. \$ 170(e)(3) (2006).

52. See id. See also Guilloux \& Moon, supra note 1, at 196 (describing enhanced deductions under the I.R.C.).

53. I.R.C. § 170(e)(3)(A)(i).

54. Id. $\S 170(\mathrm{e})(3)(\mathrm{A})(\mathrm{iv})$.

55. Russo, supra note 50, at 1.

56. Id. 
with WHO guidelines, ${ }^{57}$ despite proposals for same, ${ }^{58}$ several major pharmaceutical companies, including Merck, ${ }^{59}$ have pledged to follow the guidelines and have procedures in place to ensure the quality of donations.$^{60}$ In addition, while deductions "are generally limited to the cost or basis of the goods,"61 under Section 170(e)(3), the enhanced deduction allows a drug company to deduct the lesser of either the cost basis plus half the difference between cost of the good and fair market value (FMV) or twice the cost basis. ${ }^{62}$ The cost of goods does not normally include research and development expenses or marketing and administrative costs; 63 however, because many '"costs of goods' costs are fixed" and economies of scale are generally available, ${ }^{64}$ the tax deduction may be higher than the marginal cost of producing the donated drugs. ${ }^{65}$

Theoretically, under these guidelines, a company can lower its taxable income by up to $70 \%$ of the cost of producing the donation, considering that the maximum corporate rate in the United States is currently $35 \% .{ }^{66}$ In such an instance, the cost to taxpayers may range anywhere between " $10.5 \%$ to $21 \%$ of the FMV of the donated product." 67 However, because "charitable contributions are capped at $10 \%$ of a company's taxable income,"68 corporations, especially large pharmaceutical companies such as Merck or GlaxoSmithKline, are unlikely to get a full tax reduction. ${ }^{69}$

57. See generally WHO GUIDELINES, supra note 7 (explaining current WHO Guidelines for medicine donations).

58. Russo, supra note 50, at 2-3. Congressman Lloyd Doggett (D, TX) proposed to disallow the charitable tax deduction on donations unless they comply with WHO guidelines. Id. Upon proposal of the bill, a request was made to the Congressional Accounting Office (GAO) to estimate the savings the bill would bring to the US Treasury but, according to GAO, such estimates were not feasible due to the relatively small number of firms that take advantage of the tax deduction. Id.

59. Merck, Public Policy Statement: Charitable Product Donations (2010), available at http://www.merck.com/about/views-and-positions/charitable-product-donation s.pdf.

60. See, e.g., id.; Crooks, supra note 4.

61. Guilloux \& Moon, supra note 1, at 196.

62. The FMV refers to the selling price of the drug in the United States. Id.

63. See id. at 195; Manon Ress, Tax Deductions for Pharmaceutical Drug Donations, CONSUMER PROJECT ON TECH. (June 29, 2000), http://www.cptech.org/ip/health/econ/tax code.html.

64. Ress, supra note 63.

65. Id.

66. Guilloux \& Moon, supra note 1 , at 196 (stating that the $70 \%$ is calculated by multiplying the maximum tax rate of $35 \%$ by twice the cost basis); see generally I.R.C. $\S$ 170(e)(3) (2006).

67. Guilloux \& Moon, supra note 1, at 197.

68. Id.

69. See id. 
While accusations that "U.S. tax laws make it possible to make money out of worthless drugs" 70 sound catchy, especially in light of prior incidents with inappropriate donations, ${ }^{71}$ the above analysis of the Tax Code suggests otherwise. The donation may not include so-called worthless drugs ${ }^{72}$ if a fair market value has to be assigned to earn tax credit. Such criticisms likely misconstrue issues regarding the appropriateness of donations, and the motives behind them, without actual evidence to the contrary. ${ }^{73}$ Moreover, while it would be nearly impossible to ascertain the motivations of individual drug companies at any given time, it would appear that if the criticisms were true and tax incentives indeed allow companies to "make money" from donations, ${ }^{74}$ far more drugs would be donated to cash in on tax deductions. ${ }^{75}$ Also, while it is possible that some drug companies have donated for venal reasons in the past, it is difficult to explain, from an economic standpoint, why drug companies collaborate and devote additional resources such as managerial assistance ${ }^{76}$ if their main goal is financial gain. ${ }^{77}$ Critics who shun drug donations because of tax incentives also appear to have an unrealistic expectation that the industry should be somehow expected to "incur losses ad infinitum,"78 which would place it at a "significant disadvantage in its ability to compete for capital and other resources with other industries."79

Overall, the debate regarding the significance of tax incentives detracts from the main issue of whether donations can be helpful in improving access to medicines in the developing world, and if so, what

70. Russo, supra note 50 , at 1 .

71. See id.

72. Id.

73. See generally WHO Guidelines Evaluation, supra note 10 (pointing out that problems with donations arise out of miscommunication and problems with customs clearance).

74. Russo, supra note 50, at 2 (emphasis omitted).

75. Id. This assumption is further based on GAO's inability to calculate the impact of tax deductions on the U.S. treasury. See id. at 2-3.

76. See id. at 3 (referring to pharmaceutical companies offering assistance for management and processing of drug donations, as well as expanding plant capacity to facilitate donations).

77. Promotion of company image and goodwill partly contradicts this argument, but given the overwhelmingly negative publicity of drug donations, companies are conceivably taking a huge public relations risk by participating in such programs. See generally Crooks, supra note 4.

78. Bryan Mercurio, Resolving the Public Health Crisis in the Developing World: Problems and Barriers of Access to Essential Medicines, 5 Nw. J. INT'L HUM. RTS. 1, 27 (2006).

79. Id. 
can be done to promote the practice rather than curb a financial motivator. ${ }^{80}$

\section{Social Incentives: Company Image, Employee Morale}

Although difficult to measure and predict, social incentives such as boosting employee morale, improving company image, and increasing good will certainly play a role in informing companies' decision to donate. In fact, the increased popularity of practices such as socially responsible investing ${ }^{81}$ and cause-related marketing ${ }^{82}$ suggests that businesses are progressively incorporating philanthropy because "social responsibility is viewed as an investment by corporations." 83 In that sense, drug donation programs can attract investors looking to "catalyze positive change in society at large," 84 enhance corporate image, and even thwart negative publicity. ${ }^{85}$ Evidence for the effect of indirect economic incentives can be gleaned from the tremendous success of Merck's Mectizan Donation Program, 86 which has received a number of recognition awards from international organizations that invariably have improved Merck's image as a "good corporate citizen." 87

Successful philanthropic donations serve the additional purpose of improving employee morale by making employees feel they are a part of a significant global effort to further a noble cause.88 Similarly, public perceptions of a company are, in part, dependent on the causes it supports and the extent of its commitment to altruistic deeds beyond

80. From a social perspective, the tax deduction can also be considered a symbol of the American public's altruism. By offering to forfeit the tax revenue that would otherwise be collected, the American public is making a statement that it wishes to promote drug donations and aid the developing world, which in itself is worth remembering.

81. Steve Schueth, Socially Responsible Investing in the United States, $43 \mathrm{~J}$. BuS. ETHICS 189, 190 (2003) (defining socially responsible investing (SRI) as "the process of integrating personal values and societal concerns into investment decision-making”) (emphasis omitted).

82. P. Rajan Varadarajan \& Anil Menon, Cause-Related Marketing: A Coalignment of Marketing Strategy and Corporate Philanthropy, 52 J. MKTG. 58, 59 (1988) (describing cause related marketing as a program that "strives to . . . improve corporate performance and help worthy causes ... by linking fund raising for the benefit of a cause to the purchase of the firm's products and/or services").

83. Id. at 58 .

84. Schueth, supra note 81 , at 190 .

85. Varadarajan \& Menon, supra note 82 , at 60 .

86. See infra Part II.A.

87. Philip E. Coyne \& David W. Berk, World Health Org., The Mectizan (IVERMECTIN) DONATION PROGRAM FOR RIVERBLINDNESS AS A PARADIGM FOR PHARMACEUTTCAL INDUSTRY DONATION PROGRAMS 16 (2001), available at http://apps.who.

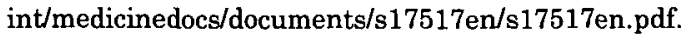

88. Id. 
profits. Consequently, donations carry tremendous potential to affect, both positively and negatively, ${ }^{89}$ a company's public image and the good will associated with it.

\section{What ARE TARGETED, NONEMERGENCY DONATIONS AND DO THEY WORK?}

Although lacking any scientific definition, for the purpose of this Note, targeted, nonemergency donations refer to formal donation programs between private and public parties organized to treat a specific, targeted disease or aid in the development of a public health care system or an aspect of it. 90

Targeted development donations differ from donations in response to emergency situations in that they involve collaboration between the parties and more extensive planning. ${ }^{91}$ In fact, to maximize the positive impact of such donations, "effective communication and negotiation between donors and recipients" is essential for ensuring that the needs of recipients are properly met, ${ }^{92}$ as suggested by the WHO Guidelines. However, maintaining such open channels of communication is not always an easy task, even with targeted donation programs, because "donations often flow across several layers of organizations, over language and cultural barriers, and through differentials of power and poverty." 93 Even so, existing targeted donation programs have made great strides in alleviating medical treatment for a number of endemics despite the fact that "data measuring actual improvements to access as a result of donation programs are scarce" due to the relative novelty of "major disease-specific drug donations." ${ }^{4}$ Nevertheless, the following subsection presents what limited statistics are available about major existing programs and considers the benefits as well as pitfalls of such initiatives.

89. See generally Crooks, supra note 4 (illustrating the effect of failed donation efforts on the image of pharmaceutical companies).

90. This definition most closely reflects product-specific donation programs as defined in COYNE \& BERK, supra note 87, at 7. However, it attempts to expand the definition of such non-emergency donations by including drugs outside the current scope and in particular those whose access is currently impeded by TRIPS patent restrictions. See infra Part III.

91. For examples of emergency donations, see generally Autier et al., supra note 6; Aplenc et al., supra note 20.

92. Autier et al., supra note 6 , at 1 .

93. Id.

94. Guilloux \& Moon, supra note 1, at 191. 


\section{A. Existing Programs}

Dating back to 1987, the forerunner of all targeted donation programs is Merck's donation of Mectizan for treatment of onchocerciasis, also known as river blindness. The company pledged to "donate the drug to all who need it for as long as needed."95 Since then, Merck has provided "well over 100 million treatments . . . for onchocerciasis." 96 The treatments spare individuals with advanced onchocerciasis from "inexorable progression to blindness," 97 as well as relieve milder, dermatologic symptoms of the disease. ${ }^{98}$ The Mectizan initiative is a public health-oriented program in that "the donated product is administered to an entire community,"99 and efforts are made to limit further transmission of the disease. ${ }^{100}$ The program benefits "[c]ommunities otherwise lacking access to appropriate pharmaceuticals." 101 In the absence of Merck's initiative, individuals in countries with the river blindness endemic would "totally lack access to an effective and safe . . . drug."102 In addition, Merck's Mectizan program does not merely deliver a drug but has effectively established "the rudimentary basis for a functioning health care system" due to Merck's involvement with the entire community and the elaborate network of parties involved.103 To ensure oversight and proper administration of the program, the Mectizan initiative is run by an external entity, the Mectizan Donation Program, which is separate from Merck as a corporation. ${ }^{104}$ Notably, although Mectizan is donated, the company is still responsible for "adverse drug effects."105 It is also subject to investigation by drug regulatory authorities such as the Food and Drug Administration (FDA). ${ }^{106}$ As one can imagine, such liability adds additional "drain on company profits" and requires maximum efficiency and use of tax benefits to avoid impinging on the tolerance of major stakeholders. ${ }^{107}$

95. COYNE \& BERK, supra note 87 , at 11.

96. David Henry \& Joel Lexchin, The Pharmaceutical Industry as a Medicines Provider, 360 LANCET 1590, 1590 (2002).

97. COYNE \& BERK, supra note 87 , at 9 .

98. Id.

99. Id. at 8.

100. Id.

101. Id. at 15 (emphasis omitted).

102. Id.

103. Id.

104. Id. at 13 .

105. Id. at 12 .

106. Id.

107. Id. at 18 . 
Another major pharmaceutical company, Britain's GlaxoSmithKline (GSK) has a similar donation program and has pledged to "supply all the albendazole needed to eliminate lymphatic filariasis worldwide by $2020 . " 108$ From 2000 to 2010, GSK donated over 2.6 billion treatments to fifty-eight countries, ${ }^{109}$ which over a period of seven years has had an economic impact of $\$ 24$ billion, 110 costing the company $£ 12$ million a year. ${ }^{111}$ Otherwise, the program is very similar in structure and function to the Mectizan initiative, except that GSK does not receive a tax break for its donations. ${ }^{112}$

On the other hand, Pfizer has pledged to a somewhat more limited donation program by offering to supply fluconazole for the treatment of cryptococcal meningitis (an AIDS-related infection) only in South Africa, without extending the offer to other sub-Saharan countries. ${ }^{113}$ Although the precise reasons for the restriction are unclear, Pfizer has faced criticism regarding the limitation. ${ }^{114}$ On one hand, such criticisms are valid in that they highlight inadequacies of donations to meet all need. On the other hand, it is unfair for companies like Pfizer to take the brunt of the criticism even when they appear to be genuinely interested in helping. For example, while the limited donation of fluconazole has garnered most of the negative attention, the company has also pledged to provide an unlimited supply of Diflucan, an antifungal AIDS medicine, in all fifty AIDS-ridden countries identified by the United Nations. ${ }^{115}$ This negative publicity highlights the disapproving attitude of critics for whom every philanthropic gesture by the corporate world is seen through a cynical lens and found to be inadequate unless completely altruistic-a near impossibility given realities of fiscal sustainability and warranted self-interest.

108. GlaxoSmithKline, UNITING TO COMBAT NTDS, http://www.unitingtocombatntds.org/ endorsement/glaxosmithkline (last visited Nov. 14, 2013).

109. Id.

110. $I d$.

111. Rachel Cooper, GlaxoSmithKline Ups Albendazole Worm Drug Donation, TELEGRAPH (Oct. 14, 2010, 6:30 AM), http://www.telegraph.co.uk/finance/newsbysector/ pharmaceuticalsandchemicals/8062194/GlaxoSmithKline-ups-albendazole-worm-drugdonation.html.

112. $I d$.

113. Henry \& Lexchin, supra note 96 , at 1590.

114. $I d$.

115. Pfizer to Donate Anti-fungal AIDS Drugs, CNN.com (June 6, 2001, 3:32 PM), http://edition.cnn.com/2001/HEALTH/conditions/06/06/pfizer.un/. 


\section{B. Potential Concerns with Targeted Donations}

While all four of the above-mentioned programs appear successful and helpful on their face, valid questions exist regarding the long-term impact of such donations. Given the long-term goals of such initiatives, final success can only be ascertained if "the effort is sustained until the job is done."116 In addition, many experts express concern that the greatest danger associated with long-term donation programs is the risk of dependency whereby developing countries fail to improve internal capacity to provide the needed medicines because they rely on the promise of ad infinitum support. ${ }^{117}$ Moreover, there are sustainability issues related to using targeted donations as a long-term solution to the access to medicine problems. ${ }^{118}$ Those sustainability concerns are further exacerbated by the fact that donations can feasibly fill only a fraction of all the existing medical need.119 Certainly, such concerns are valid, and this Note does not suggest that donations are a long-term solution or the sole solution to the problem. Rather, this Note argues that donations should be encouraged as a complimentary solution.

Some argue that administration and management of donations in the recipient countries divert "scarce human resources [away] from existing health structures" and present additional burdens. ${ }^{120}$ The storage and distribution of supplies often prove difficult for developing countries that lack the infrastructure and resources to handle them and may "give rise to numerous problems . . . ranging from technical failure to staff corruption." 121 To ameliorate technical problems, building additional structures might be necessary to process and utilize donations even if it costs recipients some of their already limited funds. However, it appears that any possible cost of construction would be outweighed by the benefit of the donations. Considering the extensive planning that goes into long-term, targeted programs, recipient countries can refuse the donation if it places an insurmountable burden on their existing structures, or they can find alternative ways to fund the additional administrative work. Some also argue that, because donations enter the drug markets of developing countries, they may be harmful to the developing countries' generic industries and act as unfair

116. COYNE \& BERK, supra note 87 , at 19.

117. See Guilloux \& Moon, supra note 1, at 191.

118. Id.

119. Id.

120. Id. at 192.

121. Frederick M. Abbott \& Graham Dukes, Global Pharmaceutical Policy 125 (2009). 
competition. ${ }^{122}$ This argument is based on the idea that generic products cannot realistically compete with free medicines, and, therefore, donations infringe on the generic industries of developing countries that some feel should be protected. ${ }^{123}$

Generally, the above-listed concerns are important to keep in mind when planning and evaluating potential drug donation programs as they can impede their success. However, these issues are only a very broad overview of potential problems with targeted donations and are by no means an exclusive list. ${ }^{124}$

\section{The Post-TRIPS ENVIRONMENT AND ROAD BLOCKS TO ACCESS}

Since the original TRIPS Agreement, there has been heated debate regarding the nature, flaws, and potential impact of, arguably, the first "harmonized approach" members of the World Trade Organization (WTO) have taken to protect the rights of intellectual property rights holders, ${ }^{125}$ including medical patent owners. ${ }^{126}$ This section does not seek to refute or comment on any existing literature but rather to provide a brief overview of the significance of TRIPS in relation to the access to medicine crisis in the developing world and, specifically, the potential for targeted drug donations to ameliorate existing TRIPSrelated problems.

In broadest terms, the purpose of the TRIPS Agreement is to allow " $[\mathrm{t}]$ he protection and enforcement of intellectual property rights" between states to encourage "technological innovation and ... the transfer and dissemination of technology." 127 Although theoretically sound, TRIPS commentators have pointed out that such stringent protection has largely been to the benefit of pharmaceutical companies in developed nations, while limiting generic producers in developing countries from manufacturing patented drugs. ${ }^{128}$ Skeptics have argued that "strong patent rights serve principally to transfer income from poor countries to rich ... [and] the social costs of patent[s] . . outweigh any

122. Guilloux \& Moon, supra note 1, at 192. See infra Part III, for further discussion of this argument.

123. Guilloux \& Moon, supra note 1, at 192.

124. See generally Guilloux \& Moon, supra note 1 , for additional concerns with donation programs.

125. Mercurio, supra note 78 , at 4 .

126. Id. Particularly, Article 27 of TRIPS extends patent protection to pharmaceuticals. See TRIPS Agreement, supra note 16, art. 27.

127. TRIPS Agreement, supra note 16, art. 7.

128. See Marla L. Mellino, The TRIPS Agreement: Helping or Hurting Least Developed Countries' Access to Essential Pharmaceuticals?, 20 FORDHAM INTELL. PROP. MEDIA \& ENT. L.J. 1349, 1353 (2010). 
potential benefits." 129 Supporters of TRIPS and international patent rights, on the other hand, argue "the protection . . . is in the interest of the developing world," 130 because it "may provide an incentive for firms to invest in research and development." 131 However, this prognosis has not been substantiated by concrete evidence to date, probably because of the number of extensions for TRIPS enforcement that have been given to developing and least-developed countries. ${ }^{132}$ Critics have also pointed out that even with such lengthy implementation periods and exceptions built into TRIPS, the enforcement of TRIPS still results in gains for developed nations. ${ }^{133}$ The exceptions were formally clarified during the Fourth Ministerial Conference, held in Doha, Qatar in 2001, where Member States adopted a Declaration on TRIPS and Public Health (the Doha Declaration), ${ }^{134}$ which has been considered the first significant victory for developing countries in the pharmaceutical field. ${ }^{135}$

Paragraphs one through five of the Declaration specifically outline the flexibilities in the Agreement intended to cater to the developing world. ${ }^{136}$ Paragraph four states that promoting access to medicines is a legitimate basis to allow developing countries to "enact exceptions to patent protection in their domestic legislation." 137 This is related to the original TRIPS Article 31(f), which outlines the conditions allowing developing countries to issue "compulsory licenses" to domestic manufacturers in cases of emergency. ${ }^{138}$ However, although aimed to aid developing countries, the article, in effect, prevents a country "from benefiting from the compulsory licensing provision if it does not have sufficient manufacturing capabilities because, in practice, the provision limits the licensee's ability to export medicines to a country with public health needs, thereby preventing countries with insufficient or no manufacturing capabilities from taking advantage of the provision." 139

129. Thomas F. Cotter, Market Fundamentalism and the TRIPS Agreement, 22 CARDOZO ARTS \& ENT. L.J. 307, 313 (2004).

130. Id.

131. Id. at 314 .

132. See id. at $312-14$.

133. See, e.g., Keith E. Maskus, Intellectual Property Rights and Economic Development, 32 CASE W. RES. J. INT 'L L. 471, 488 (2000) (pointing out that although TRIPS may act as a catalyst for $R \& D$ of endemic diseases in the future by increasing pharmaceutical profits that might get reinvested, it is unlikely that it will improve access to patented medicine in impoverished countries); Mellino, supra note 128, at 1353.

134. Doha Declaration, supra note 17.

135. See, e.g., Bryan C. Mercurio, TRIPS, Patents, and Access to Life-Saving Drugs in the Developing World, 8 MARQ. INTELL. PROP. L. REV. 211, 228 (2004).

136. See Doha Declaration, supra note 17, 1 1-5.

137. Mercurio, supra note 78 , at 6 .

138. Id. at 7.

139. Id. 
To remedy that, a subsequent agreement, the Implementation of Paragraph six of the Doha Declaration on TRIPS Agreement and Public Health (Implementation Agreement), ${ }^{140}$ was reached, which "allows nations with insufficient or no manufacturing capabilities to override intellectual property protection and import generic copies of patented drugs to combat public health crises." 141 Still, "in order to be TRIPS compliant, the importing Member must abide by several procedural steps," such as notifying the TRIPS Council of the "names and expected quantities of the products needed." 142

Unfortunately, even with the listed exceptions and flexibilities that the international community has afforded to developing countries in situations of national emergency, the practical result of TRIPS is that, due to a multitude of external factors including "lack of political will" demonstrated by the governments of developing countries and deepseated socio-economic issues, ${ }^{143}$ the access to medicine remains impeded and stalled. In addition, the fact that such exceptions are limited to situations of national emergency certainly excludes a number of drugs that may not rise to the level of emergency but are likely needed and cannot be afforded by developing countries under the current system.

\section{RECOMMENDATIONS}

\section{A. Expand Targeted Donation Programs}

Given the current state of crisis, the question of how to improve access to medicines remains. This Note poses that targeted drug donation programs should be expanded and promoted to fill the gap of nonemergency, but nevertheless vital, medicines that developing countries find difficult to obtain given increased patent protection under TRIPS. Although general concerns of sustainability and scale remain valid and prevent donations from being the sole, long-term solution to the problem, given the relative success of such programs, ${ }^{144}$ they are certainly a valid alternative.

Unfortunately, current donation initiatives remain limited to large, multinational corporations for a number reasons, including the lack of economies of scale and diminished social incentives for smaller, lesserknown efforts. To harness all the available power of donations, the

140. WTO General Council, Implementation of Paragraph 6 of the Doha Declaration on the TRIPS Agreement and Public Health, WT/L/540 (Aug. 30, 2003).

141. Mercurio, supra note 78 , at 8.

142. Id.

143. Id. at 24.

144. See supra Part II. 
international community should make a concerted effort to strike a fair balance between objective evaluation and fair criticism about donation programs and blatant, often unsubstantiated blame, which overall increases the risk for companies to donate if they are likely to face public scrutiny and reproach. Current misconceptions about donation programs in general and overall distrust toward the corporate world's philanthropic efforts act as a buffer, preventing a needed healthy discourse about the realities of business decisions and the needs of developing countries.

On that note, the idea of an independent international organization vested with the task of coordinating international drug relief efforts might be a sound solution to current criticism about transparency. An entity that can perhaps be emulated in structure and function is the United States Agency for International Development (USAID). ${ }^{145}$ USAID currently regulates a broad array of initiatives, including U.S. government-sponsored food relief efforts, emergency food assistance, and long-term development programs. ${ }^{146}$ It also lists "global health" as one of its programs, ${ }^{147}$ which is primarily focused on investments in maternal and neonatal health.

Considering that USAID is an established entity with a long history of regulating relief efforts, it might be worth expanding its initiatives to include monitoring of drug donations, or, at the very least, it should be used as a resource for the international community to imitate its structure and establish a similar entity to regulate international drug relief efforts. If better care is taken to monitor and record the figures surrounding donations, including total tax deductions obtained, perhaps the international community can move away from bickering about the nobility of corporate intentions and focus on the benefits donations can offer.

\section{B. Use a Voucher System in Conjunction with Tax Deductions}

An additional solution to concerns that tax deductions for pharmaceutical donations are costly to the taxpayers is offering an alternative financial incentive, ${ }^{148}$ which would be beneficial to

145. See generally U.S. AGENCY FOR INT'L DEV., http://www.usaid.gov (last updated Sept. 30, 2013).

146. See Who We Are, U.S. AGENCY FOR INT'L DEV., http://www.usaid.gov/who-we-are (last updated June 12, 2013).

147. Global Health, U.S. AGENCY FOR INT'L DEv., http://www.usaid.gov/what-we-do/glob al-health (last updated Nov. 7, 2013).

148. See generally Guilloux \& Moon, supra note 1 (using various models to calculate the cost of drug donations to U.S. taxpayers). 
pharmaceutical companies in light of the current industry environment. One possible supplement to tax deductions is the use of a "priority review voucher," 149 as proposed by David B. Ridley et al. ${ }^{150}$ The voucher would allow drug companies to obtain a speedier, priority review status when waiting in line to have a drug approved by the FDA. ${ }^{151}$ Although the voucher system was originally proposed as an incentive to encourage the research and development for neglected diseases, ${ }^{152}$ it appears transferrable to drug donations and offers a number of useful benefits that address some of the issues previously discussed.

The voucher would allow manufacturers to bring a high-value drug of their choice on the market faster, which would likely increase returns exponentially, especially for successful, blockbuster drugs.153 The voucher can be a great incentive for companies to increase donation efforts, and it might eliminate the tax deduction if companies choose to seek a voucher instead of a deduction. A priority review voucher would "not entail lower standards for safety and efficacy," 154 although it might require the FDA to expand additional resources to handle the voucher applications, which have been estimated at 1 million dollars. ${ }^{155}$ To compensate for that, the FDA may require drug companies to pay a so called "user fee" in full, ${ }^{156}$ or the fee could be governmentally subsidized depending on the extent and nature of the donation. By requiring manufacturers to pay the user fee, taxpayers' dollars would be saved in cases where companies opt for the voucher instead of the tax deduction. Considering that tax deductions are difficult to estimate, it is hard to tell what the exact savings to taxpayers will be, but, in any event, careful planning is needed to prevent abuse of the voucher system. ${ }^{157}$

Given the limited amount of vouchers that can be made available without backlogging the FDA system, the incentive must be tied to very

149. David B. Ridley, Henry G. Grabowski \& Jeffrey L. Moe, Developing Drugs for Developing Countries, 25 HEALTH AFF. 313, 313 (2006).

150. Id.

151. See id.

152. Id.

153. See id. at 315 (estimating that priority review vouchers would be worth more than $\$ 300$ million for potential blockbuster drugs, because they would shorten the time the FDA takes to approve them and therefore allow companies to get drugs to the market sooner).

154. Id.

155. Id.

156. Id.

157. Considering the highly competitive nature of the drug industry, one can imagine that getting in front of the FDA line for approval carries a lot of value for pharmaceutical companies facing patent expiration dates and generic competition. Consequently, it must be ensured that companies would not simply produce unnecessary drugs and promise to donate them in exchange for getting a bite of a priority review voucher. 
specific and highly regulated eligibility requirements regarding the quality and type of drug donations qualified for the voucher. For example, companies might be required to comply with WHO's recommended guidelines or required to make a time commitment to a particular donation program.

As far as the interchangeability of tax deductions and review vouchers, the two systems must be complimentary because, depending on the established guidelines to qualify for priority review, most donation programs might be excluded due to scale or other reasons. Therefore, both incentives are needed to encourage drug companies to donate without disadvantaging themselves. Overall, the feasibility of using a voucher system would depend on additional analysis of how the system can be balanced to incentivize without unduly disrupting the current market, but it appears to offer a number of benefits that might promote drug donations.

\section{CONCLUSION}

In an era of increased technological and scientific advances, it appears incumbent upon all of society to take action and not stay idle in the face of great human suffering. Although imperfect, drug donation programs are capable of at least partially bridging the existing access to medicine gap. Therefore, the international community should pay more attention to what drives drug donations to better understand how they can be effectively promoted and maximized to their full potential. In addition, the issues related to balancing patent rights and the needs of developing countries under TRIPS can only be resolved through "persistent action, in the framework of consistent international cooperation ... for the vicious circle of disease and poverty to be broken."158 With that in mind, less finger pointing and enhanced knowledge about the extent of drug donations is likely to result in a much more productive dialogue than currently exits.

158. José Luis Valverde, Toward a Global Legal Statute for Medicinal Products, in 9 KEY ISSUES IN PHARMACEUTICALS LAW 273, 277 (José Luis Valverde ed., 2007). 